Journal of Education and Vocational Research

Vol. 4, No. 9, pp. 246-253, Sep 2013 (ISSN 2221-2590)

\title{
Preparation of Principal for School Change: A Singapore Perspective
}

\author{
Babin Pokharel \\ Kathmandu University School of Education, Nepal \\ babinpokharel@gmail.com
}

\begin{abstract}
This paper examines the understanding of the educational leadership process and the exploration of systematic preparation of private school principal in order to cope with future school change. Leading through change in education is a must in $21^{\text {st }}$ century. Various contexts determine the change in leadership process. In schools, principal needs to be prepared in order cope with contextual changes. Changes in school can be seen various contexts such as cultural, technological, policy level, outbound competitions so on and so forth. School principal are the most important catalyst in the construction of new and innovative leadership practices that enhance the change process. Specifically, it presents the findings from the case of four private schools principal in Singapore through their storytelling. This paper includes an overview of the study and a discussion of growing themes related to the leadership process of the principals and their preparation strategy for a school change. The results from this study indicate how school principal prepare themselves for future and school change taking the entire internal and external environment into consideration.
\end{abstract}

Keywords: Principal; school leadership, change, preparation, private school

\section{Introduction}

Republic of Singapore, independent republic in Southeast Asia provides extra incentives to healthcare and education to its citizen. Singapore's government policy strengthens its population by providing innovation in education sector and major part of budget is allocated for the innovation and transformation of education system predominantly challenging the global scenario. Hence Singapore being one of the prominent country for education especially for perusing higher education. The aggressive technology policy of the government has invited capitals in the form of foreign direct investment in the fields of biotechnology, IT and research. The Ministry of Education (MOE) is responsible for controlling the development and administration of the schools whether it's private or public or international and various government-funded educational institutions. In case of private schools in Singapore, the MOE plays a crucial supervisory and advisory role. Education in Singapore is identified in the ease of the Singaporean students. Their interest and perception are channelized with the curriculum design which helps them to circulate in the mainstream education scenario. According to MOE, the teaching and pedagogical system follows a flexible approach that helps the students in developing their potentials and. The MOE being the main body to regulate and facilitate education system in Singapore aims to help all the institution either private or public owned and always encourage students towards innovation and experiencing their full potential to penetrate in their life which will eventually also develop a passion for learning that lasts through their life.

Research findings from a variety of countries and school systems draw similar conclusions about the importance of the principal in school development and change processes (e.g. Van Velzen et al., 1985; Duignan \& Macpherson, 1987; Myers \& Murphy, 1995; Ainscow et al., 1994; Stoll \& Fink, 1996). They have identified consistently that those school principal, which have demonstrated the capacity to prepare and improve themselves, tend to be led a significant contribution to the effectiveness of their staff and school environment. The school principal's change process has to be foreseen in accordance with the environmental factor which includes cultural, political, technological and economical. School principal have to interact with these entire environmental context in order to tackle the change that they will experience in the future. Direct changes in the educational system have a particularly strong and, to a large extent, calculable impact on the school principal's role. Moreover is also known that schools, and consequently the pressures and expectations on school leaders, also change as a result of more subtle and indirect forces in society - social, political and economic changes - that are gathering pace across the world as the speed of international 
development increasingly reflects global factors. (Van Velzen et al., 1985; Duignan \& Macpherson, 1987; Myers \& Murphy, 1995; Ainscow et al., 1994; Stoll \& Fink, 1996). These new kind of environments can really bring higher impact on school principal that will facilitate the process of leading change and bring out different dimension of risk, challenges and new task, nevertheless there is some concern that what we are trying to do is to prepare principal for tomorrow's schools using today's various new method incorporated by countries prominent in educational sphere.

\section{School Principal: At a Glance}

Leadership is defined as the ability to get all members of the organizations to perform tasks required to achieve the organization's goals and objectives (Bennis \& Nanus, 1985). As leadership practice determines the success and efficient running of the school, better leadership enhances all the contextual progress inside the school such as teaching and learning, community support and growth of school as a whole. Good school principal are always in the betterment of school through communicating the corporate and ethical values to its staff. The communication of values and vision plays an important role in shaping the school principal leadership practices. School principal do face complex environment and changing scenario in the educational sphere, which sometimes bound them to prepare and walk with the change which they need. They must coordinate the services offered to their students, and to ensure that these services reach those with the greatest needs; and at the same time to ensure that there is no disruption of the teaching and learning process in school. The dramatic reform initiatives that characterize education, and specifically the school sector, are placing a range of new demands on education systems around the globe. Main global trend such as the transformation in school and role of principal are currently posing huge and complex international questions for education (Portin, Schen \& Williams, 1998; Pretorius, 1998)

School Principal is equally responsible of identifying five control parameters that determine the state of the system in which change agents function. These are rate of information flow, connectivity, diversity, power differentials and anxiety. School principal have to give much priority to the marketing of their schools, i.e., to enhance the school's image, recruitment and retention of students (Smith, 2003). The review of leadership literature has led to an initial identification of the six characteristics of leaders of educational change (Morse, 1992), which are:

- believing that the schools are for learning,

- valuing human resources,

- being a skilled communicator and listener,

- acting proactively, and

- taking risks.

Leadership in systems engaged in change must be prepared to tackle problems that have unknown solutions and unpredictable outcomes. Key characteristics of change-focused school principal include communicating vision, understanding of the change process, and the abilities to build relationships, to create and share knowledge and to make the change process coherent to others in the organization. Principal who foreseen change must propitiate the school vision with learning centre with continuous change process. The top most idea of being a school principal is valuing all the staff and channelizing effective communication in the entire school. Principal who leads and support educational change is parallel with all the staff and the jobs that are performed inside the school. "Effective change requires skilled leadership that can integrate the soft human elements with hard business actions" (Joiner, 1987, p. 1).

If school leaders are to be proactive, they need to have reality check on how to lead and support educational change. The importance of knowledge that are shared through series of experience need to be addressed by the principal and needs to find out strategies required to manage these change. In educational organizations there is an assumption that leaders of educational change should be both leaders and managers. "We expect both leadership and management from the same individual". Nevertheless, "while we can distinguish management from leadership conceptually, in reality we often find the two roles coexisting in the same positions and the same person" (Manasse, 1986, p. 153). For instance, a principal is often responsible for the school's vision as well as the steps needed to attain that vision. Therefore, school Principal should have an understanding of the "real issues" which facilitate the smooth operation of school. Effective school principals 
in the modern age should possess certain future qualities of leadership that distinguish them from their peers (Greenfield \& Ribbins, 1993). Qualities needed for future school operation such as reflection, vision, commitment, courage, power, and empowerment come immediately to mind when one thinks about excellence in future principalship (Steyn, 2002).

School Principal in Singapore: An Overview: The approach to education change in Singapore, which has considered being one of the world's leading education systems (Ng, 2003). Emerging from colonialism in the 1960s, the government prioritized providing high-quality education to all students, and then integrated education change into a broader deployment of technology under the framework of IT2000: The Intelligent Island. Responsive leadership throughout this period ensured all school principal that learning was incorporated into all levels of the education system, and that processes of ongoing development and innovation were mainstreamed. Key practices that evolved in Singapore can be adopted by other education systems, regardless of whether they have built the capacity to immediately open themselves to participation in knowledge societies. These key practices include:

- Commit to inclusively

- Integrate teaching practices, learning objectives and content

- Link the outcomes of change to policy goals

- Focus on changing practice, not on technology

In the 1960s, Singapore's massive curriculum-reform initiative became the starting point for ongoing change for the school principal. Dr. Ruth Wong, founding director of the National Institute of Education, recognized that new approaches were always needed for curriculum and school leadership, and that these approaches should be based on understanding of the challenges at the grassroots level: she spent three months visiting schools and talking to teachers and principals. Educational transformation, as exemplified by Wong's activist leadership, has been distinguished first and foremost by actions intended to remake the educational system top-to-bottom into a learning system - a system that employs research that rewards innovative leadership that promotes teachers' development and that focuses all of these learning activities on improving student outcomes. And education-technology has been integrated into all aspects of school culture together with new technological learning for school principal to cope with the change. Therefore Singapore school principal are utmost tech-savvy and deals with ongoing change in technology. Singaporean school principal are preparing themselves for all sort of changes and innovation that is required by their school. The key challenges, therefore, confronting to school principal operating their school should understand how to anticipate the variation of their school change and the modality to be prepared for the future. The knowledge, skills and competencies that the new generation of school principal needs to cope up with the future school transformation are the subject area that are understood by the school principal of Singapore to deal with changes. According to MOE, there are several designed programs and finding ways to equip such transformation in Singapore's private schools are the best example that any developing countries or country like Nepal should follow in order to prepare effective principal for tomorrow.

\section{Methodology}

As this study of Singaporean school principals intends to project their experience, their real life story of process of change and process of preparation for future, the method of Narrative Enquiry is used. Narrative inquiry is the process of gathering information from the respondents in the form of storytelling. Connelly and Clandinin (2000) noted that, humans are storytelling organisms who, individually and collectively, lead storied lives. Thus, the study of narrative is the study of the ways humans experience the world. Meaningful presentation of real life experiences are gathered here through stories shared by Singaporean principal.In this study the sample is small, hence the samples are chosen randomly in regards with this study. In order to facilitate better understanding of the research, target population is randomly picked. Four private School Heads are chosen on the basis of random sampling method where they have equal chance of being selected as sample out of pool of registered private school of Singapore. Codes are given to each respondent to hide their identity as a part of ethical consideration. Few codes involved in this study are: PSP 1- Private school principal 1. PSP 2- Private school principal 2. PSP 3 - Private school principal 3 and finally PSP 4 - Private school principal 4. Although data were collected from four private school principal, this article only encompasses only few data from them to give rough idea about the scenario in Singapore. As all principal 
respondents belong to the reputed and top private schools in Singapore, hence they can sprinkle the essence needed for this article. Primary qualitative data tools such as non-participant observation and semistructured interview are carried out in this study in order to find out about the Principal leadership style and their adoptability of innovative and new technique of educational leadership. These both techniques qualifies in this study that helps to understand the leadership philosophy that are proposed to them from changing time which encourages them to change and prepare for the future.

Exploring reality of Singapore Private School Principal: "Change must be initiated by leaders who are willing to risk their reputations for the future benefit of their organization" (Joiner, 1987 p. 4). Singaporean private school principals are extreme learner and possess active participation in trainings. When asked with one of the principal respondent, He replied the scenario of Singaporean principal as; in private school of Singapore, best principals are recruited. Leadership is more students centric and holistic. In private school process of leading is top down approach, Distributed leadership is used. Also staffs are engaged in decisionmaking process. Almost every principal were teacher once so they knows educational philosophy. They are also visionary and have utmost conceptual knowledge with strong idea on curriculum and are the organization. Leader. (PSP 3).

In addition to the above statement, he also mentioned, Singaporean principal often takes risks and have tremendous benchmark for setting vision and tend to consider everyday as opportunities that will improve the organization. Leaders of change provide the needed motivation for change. They take risks and encourage others to initiate change. He also adds, School Principal in Singapore get prepared by encouraging their staff to experiment with various transformational methods to meet the academic needs of the students and bring school into new height. In the interview, one of the interviewees remarked criteria for this experimentation in following views: School Principal here are strong in organizational leadership and curriculum leadership. They have heart for students and staff. Firstly, they follow the self-reflective practice. Attend trainings, professional reading and observation. That's how self preparation for change is carried out. (PSP 3).

It has seen that notion of being excellent communicator is also one of the key attributes that Singaporean private school posses to enhance the challenges that future has to offer. Value being on of the major player in principal activities. Bringing trust to the school and with teachers and other staff can also bring heart to the organization making easier the process of change. When asked with one of the principal, he quoted, School leader in Singapore are people manager. They meticulously plan and have strong vision of school development. Finally result oriented. (PSP 2).

Both interviewees focused on being people person. Without trust and integrity, a successful principal can not posses effective result. Their statement also aids principal guides and provokes the staff to explore alternatives which are genuinely safer while transforming. They also provide a platform where collective decision making is practiced and closely monitor school's future strategy and vison. School leaders in Singapore encourages their staff to experiment transforming to meet challenges draw $\mathrm{n}$ by culture change, competitive environment and various other external changes. Prepared school principals that lead and guide others in school change take risks taking all the long-term consequences in mind which supports as the barrier to lead in changing environment. Furthermore school should also encourage the principal to move further to tackle school transformation. Private school has to develop school-based approaches. They also need to develop various leadership courses (in house and out). Coaching and mentoring is another important issues that management team have to take into account. They also need to help in the professional development of school leader. And as a simulations practice they have to create challenging work assignment. School need to help to cultivate environment to practice good leadership. (PSP 3)

It's crystal clear that Singaporean principal poses good site in changing themselves, they still lookout for the new and innovative methods as a continuous learning process. Their views showcased that there are few contexts in school in which changes occur and Singaporean private school principal grab the effective model to act on the changes that happens in school periphery.

Policy driven Preparation: When education spare is concerned, schools perform and follow general frame of systematic rules and regulation which are both patterned through international, national and local 
social/economic/cultural relations and put into and delimited by political and policy regimes. Educational policy makes a difference in the development of school capacity for better performance. Changes in policy also generate the maximum inclination of school principal towards the better adjustment and dealing for school effectiveness. When asked about the principal preparation process in Singapore by the government, one of the principal respondents added, Singapore government has many leadership courses and programs. Programs like leadership development program which can be extremely benefited to private school principal. Well in Singapore, environment is stable due to stable and innovative government. Schools also implement good and changed strategy and not only do the talking. Process of continuous improvement is present in all school of Singapore. Finally Singaporean schools are open minded (learn from the world). (PSP 4)

In Singapore, Ministry of Education creates the central policy and guideline, which draws the perimeter for operation of school and school principal modality of leading the change. Similarly they create different activities, courses and programs under leadership development department help them to fight against any transformation in future.

Culture driven Preparation: Meaningful school principal preparation begins with extensive insight on cultural change and later able to lead and adopt that cultural change. Effective change oriented principal identify and build on traditions rather than compete with them. In Singapore too, Principal have constant watch in cultural change and act in terms of those changes. Principal respondent 1 Quoted, One of the most important cultures seen in Singapore is "learning culture". Principal never stops learning new things and letting other learn from their respective school. When asked about the school culture in Singapore, another principal replied, timely I tend to make parents, students and staff aware of new school culture. (PSP 2)

School culture is guided by principal self leadership qualities. As long as he/she doesn't possess innovative style of leadership culture cannot be changed. When asked about this view to one of the principal, she remarked school culture is the projection of who am I and added, The communicating and listening skills of principals, and teachers here are the basis for their ability to articulate a vision, develop a shared vision, express their belief that schools are for the students' learning, and demonstrate that they value the human resources of their peers and subordinates. Being an effective communicator and listener sets excellent culture where everyone can expresses ideas and views. (PSP 1)

Technology driven Preparation: Among the various changes that schools have faced over the years is the technological change. There is a significant development in the use of technology inside the school. Although there is significant utilization of technology in school, principal professional development can actually look into the usage of technology in their school abd ability to cope with that technological interference in leading practice. The change process is complex and daunting. One could therefore assume that the problems and barriers associated complex change are also complex. Technological change is considered to be a major innovation not a minor one (Fullan, 1992 p. 57). As with any educational change, there are many barriers that can cause any innovation to be less than substantially realized. Technological change is no different in Singapore private school. Principal considers technological change that is supposed to change not only the way that school operates but in the way everyone including school principal would learn at school. One of the principal added his remarks in technological change and grasping this state, recently I have focused more into ICT Integration where most of the teaching and learning process is driven by technology. I have also focused more into training programs where I can get enough environment tracks. Various training programs include HR training, pedagogical training, technological training for my staffs. (PSP 4)

Competition driven Preparation: Competition is one of the major factors for any schools to show their performance and progress to the society. It is also the global driving force that facilitates any school leaders to have self motivation and leads against any competition their school faces. This phenomenon is taking the competition among schools to different heights where there is little scope for survival of school which shows resistance to change. This competition forces principal to be ready in their utmost leadership style where they can perform better with the strategy that supports the educational change. The case was similar in Singapore too. The society has become more open towards change due to high demand and remarkable global competition. One of the interviewee quotes, in other Asian countries leadership style is formal and authoritative .Here in Singapore, staffs voice is heard. Collaboration of school leader and staff are there together 
with knowledge sharing in every level. Mindset changes in Singapore. People in Singapore give high priority to changes that bring about growth so it's easier to change. (PSP 2).

In Singapore private school, Competitiveness in terms of performance and effectiveness to achieve a dominant position in the growing market place has made it compulsory for many schools to redevelop again. The same reasons push private schools having balancing strengths of school principal to change themselves through merging together with transformation characteristics and bringing innovative side of the school. Being professionally sound in their position to compete with global breakouts too proves the strength of Singaporean principal to urge for the progression. One interviewee also adds, I attend leadership training and professional conferences to gain background information. I also read articles and books on leadership to maintain myself in this competitive world. (PSP 1).

\section{Pathway to Principal Preparation: Unfolding Possibilities}

Conventional leadership which is profoundly rooted in many private schools around the world is insufficient to meet the needs of the $21^{\text {st }}$ Century leadership practice. As this new millennium brings lots of complexity, chaos, unpredictability and paradigm shift, the process of change is regular and fast. The importance of change is everywhere and it is a mandatory component. Today's school principal face most unusual challenges in their school, can be environmental challenges or contextual challenges or chaos in leadership practice. The strong trust charisma, and independent leader and transforming leadership we have idealized, strived to be proven as counter-productive in the new millennium and undermine a sustainable future (Hays \& Kim, 2001). Mutual trust between principal and all the staffs is the single most important factor within a school's culture that will allow for successful changes for improvement to be possible. Without trust there is no effective communication or collaboration, which hampers the development of commitment to school improvement (Fullan, 2001). The challenges and opportunities of principal preparation process for a new type of school principal, indeed a different way of thinking about school principal leadership practice and of developing future principal. Private school principal should explore the nature of the innovation in leading and should posse's qualities and capabilities which will be needed in the future school transformation.

Accelerating change towards Quality Education: The embarkation of Quality education is done through school principal's skills and competencies that are showcased in their respective school. Many private schools are lunching their progression chart through implication of ICTs programs. It is seen in many school that principal are gradually in the process of preparation for the knowledge-based, information society. Principal should understand that students as capital and as future recourse, which are a proper investment in the future of national economy. All this is fair and possible only through bring change to the school. And to bring the change, principal needs to be changed. Their priority should be placed on providing intensive areas of quality that are required in the school which will eventually results in creating value based students. The focus on betterment of the quality of education has become a global concern and kept as high priority in private schools. Government in countries like Singapore maintains the dignity in creating qualified person even for private sector by making school friendly policy, private institution development policy and principal training and development.

Identifying innovative leadership style: Throughout the research, I found out that Singaporean principal loves change and experiment with their leading style keeping actual meaning of contingency approach and transformational leadership style into account. In contrast many other private school principal around the world does love change as well but scared of the consequences with significant inclination towards "Transactional Leadership". With regards to the style of school management, Beare, Caldwell and Millikan (1989) distinguish between transactional and transformational leadership. Principal who are 'transactional' in their approach to school improvement try to 'sell' their ideas and demands to staff, using a combination of pressure and compensation. Transformational principal, on the other hand, improve the school through improving their leading practice, balancing the attributes of the staff inside the school. It seems many Singaporean principal undertake transformational leadership style with the touch of their own leadership practice to enhance the betterment of their school. 
"Being Transformer to tackle the Change and Trendsetter to create the Change":Bottom line, to embrace change and to create tranquility in leading school, any principal is advised to follow transformational leadership (Bass,1998) which communicates and links the school principal and their staff with the long term vision. The perception of leadership effectiveness and the enactment strategy are influenced by the societal values and the cultural context (Matveev \& Lavina, 2007). Attributes of transformational leadership vary for different cultural contexts. Therefore, principal of private school should act as "Transformer" to lead change in $21^{\text {st }}$ century. Being "Transformer" foresee the interaction between themselves and the school staffs. "Transformer" also helps in showing a relationship between leadership dimensions, individual and organizational performance outcomes, and a principal's self-reported and other-reported communication competence. As education is going global in tremendous manner. Private schools can import best education in the form of manpower, system and accreditation. Hence "Transformer" also teaches the cross-cultural communication competence which creates framework in analyzing and predicting the effective communication strategies and influential transformational leadership across different cultural contexts. I believe that unlike other superheroes like superman, Spiderman etc, principal can become "Transformer" in his school and get benefited from transformational leadership which teaches various competencies required to become prepared principal.

Personal Leadership Brand: A personal leadership brand is an exclusive and a specific approach of a leader to address challenges and manage his/her transactions with their subordinates or followers (Smallwood and Ullrich, 2008). This leadership theory gives ample space for a leader to play with his/her own leadership style, put together his leading attributes and then mould his/her leading pattern according to the required situation. It is essential for a school principal to practice own leadership brand in thoughts and actions so that their implementation in school activities can set remarkable results. It is best for the private school principal in order to get prepared in leading practice to have own leadership style. They can check their leadership brand with other school leaders to understand their expectations from the role; if there is any gap between the principal leadership brand and his action, it can be always incorporated. Apart from the above aspects, principal needs to maintain ethical behaviour and stand with exemplary achievements so that the school staffs chooses them to be a role model and redefine their perception, thoughts, mindsets and ambitions to encompass the entire school, which they represent. Hence, principal should identify objective of the school, create value based leadership and transform according to nature of environment. Creating personal leadership brand is the accomplishment of getting prepared for the change.

Allocating concrete methods for school principal preparation: This change is everything. Perhaps the greatest challenge for private school is to develop prepared principal for future-principal who leads with and through others, not over them (Kotter, 1996). While the attributes of principal are shifting from conventional understandings of leadership to transformational, from autocratic to more facilitative and power-wielding to power sharing with own leadership brand, the challenge of molding concrete methods is really crucial task. In an effort to discover best and concrete methods for school principal preparation, that too may be leadership development program which is fairly conservative and slow to change came up with mainly three concrete method which is applicable:

- Expanding Learning Opportunities

- Ample training Prospect

- Formation of Leadership Development Centre.

\section{Conclusion of the Findings}

The leadership style of Principals, motivation of teachers and other staff and organizational culture are different in different schools. While observing the leadership in private schools of Singapore has been found very different and impressive as far the leadership practice by school principal, their way of leading and supporting change, motivation of the staff and smooth running of school is concerned. Schools are in constant supervision and scrutinized policy under Singapore government drives every private school to perform better. Again the principals of the private school in Singapore are the excellent communicator, frequent learner, have open mindset and prepare themselves against all the odds and future school transformation. Policy, culture, technology and competition are the quintessential factor that provokes principals to prepare themselves for a future change. Thus the findings of this study pose a serious notion that prepared principal 
are those who are able to influence the present time. The principals should be provided proper leadership training in order to achieve a good school culture and a communication of values among staffs that are present in this new era together with full fledged preparation with all internal and external factors into consideration. Although new vision of the prepared schools principal are presented in Singaporean private schools are emerging with transformational leadership, the new goals required of them in the changing educational environment needs to be addressed and prepare accordingly.

\section{References}

Ainscow, M., Hopkins, D., Southworth, G. \& West, M. (1994). School Improvement in an Era of Change. London: Cassell.

Bass, B. M. (1998). Transformational leadership: Industry, military, and educational impact. Mahwah, NJ: Erlbaum.

Beare, H., Caldwell, B. J. \& Millikan, R. H. (1989). Creating an Excellent School London: Routledge.

Burns, J. M. (1978). Leadership. New York: Harper \& Row.

Duignan, P. \& MacPherson, R. (1987). Effective Leadership: a practical theory for new administrators. London: Falmer.

Fullan, M. (1992). Successful School Improvement. Buckingham: Open University Press.

Fullan, M. (2001). Leading in a Culture of Change. San Francisco: Jossey-Bass

Greenfield, T. B. \& Ribbins, P. (1993). Education administration: towards a human science. New York: Routledge.

Hays, J. \& Kim, Y. (2007). Renaissance Leadership: Transforming Leadership for the $21^{\text {st }}$ century. The Australian National University.

Joiner-Jr., C. W. (1987). Leadership for change. Cambridge, MA: Ballinger Publishing Company.

Kotter, J. P. (1996). Leading Change. Cambridge, MA: Harvard Business School Press.

Manasse, A. L. (1986). Vision and leadership: Paying attention to intention. Peabody Journal of Education, 63(1), 150-173.

Matveev, A. V. \& Lvina, E. (2007). Effective transformational leadership across cultures: The role of crosscultural communication competence. Paper presented at WCA 2007 Conference, Brisbane, July 2007

Méndez-Morse, S. (1992). Leadership Characteristics that Facilitate School Change. SEDL Education Research Journal, 2(4).

Myers, E. \& Murphy, J. (1995). Suburban Secondary Schools. Principals' Perceptions of Administrative Control in Schools. Journal of Educational Administration, 30(3), 77-88.

Manasse, A. L. (1986). Vision and leadership: Paying attention to intention. Peabody Journal of Education, 63(1), 150-173.

Ng, P. T. (2003). The Singapore school and the School Excellence Model. Educational Research for Policy and Practice, 2(1).

Portin, B. S., Shen, J. \& Williams, R. C. (1998).The changing principalship and its impact: voices from principals. NASSP Bulletin, 82, 1-8.

Pretorius, F. (1998). Managing the change to an outcomes-based approach. In: F Pretorius (Ed.). Outcomesbased education in South Africa. Johannesburg: Hodder \& Stoughton.

Singapore Education Policy and change, Retrieved September 2 from www.moe.gov.sg.

Smith, R. W. (2003). Confirmatory factor analysis of the Principal Self-Efficacy Survey. Journal of Organizational Culture, Communications and Conflict, 9(1), 81- 86.

Steyn, G. M. (2002). The changing principalship in South African schools. Educare, 31, 251-274

Stegö, N. E., Gielen, K., Glatter, R. \& Hord, S. M. (Hrsg.) (1987). The role of school leaders in school improvement. Leuven: ACCO.

Stoll, L. \& Fink, D. (1996). Changing our Schools: Linking School Effectiveness and School Improvement. Buckingham: Open University Press.

Ulrich, D. \& Smallwood, N. (2008). Leadership Brand: Developing Customer Focused Leaders to Drive Performance and Build Lasting Value. Harvard Business Review Press

Van Velzen, W. G., Miles, M. B., Ekholm, M., Hameyer, U. \& Robin, D. (Hrsg.). (1985). Making school improvement work: A conceptual guide to practice. Leuven: ACCO. 